\title{
Urate lowering therapy to improve renal outcomes in patients with chronic kidney disease: systematic review and meta-analysis
}

\author{
Tahir Kanji ${ }^{1,3^{*}}$, Mandark Gandhi ${ }^{1}$, Catherine M Clase $^{2}$ and Robert Yang ${ }^{2}$
}

\begin{abstract}
Background: Hyperuricemia may contribute to renal injury. We do not know whether use of treatments that lower urate reduce the progression of chronic kidney disease (CKD) and cardiovascular disease. We performed a systematic review and meta-analysis of randomized controlled trials to assess the benefits and risks of treatments that lower urate in patients with stages 3-5 CKD.
\end{abstract}

Methods: We searched MEDLINE, EMBASE, CENTRAL, Web of Science and trial registers for randomized controlled trials (RCTs) without language restriction. Two authors independently screened articles, assessed risk of bias and extracted data. Data obtained included serum uric acid, serum creatinine or other estimates of glomerular filtration rate, incidence of end-stage renal disease (ESRD), systolic and diastolic blood pressure, proteinuria, cardiovascular disease and adverse events.

Results: From the 5497 citations screened, 19 RCTs enrolling 992 participants met our inclusion criteria. Given significant heterogeneity in duration of follow-up and study comparators, only trials greater than 3 months comparing allopurinol and inactive control were meta-analyzed using random effects models. Pooled estimate for eGFR was in favour of allopurinol with a mean difference (MD) of $3.2 \mathrm{ml} / \mathrm{min} / 1.73 \mathrm{~m}^{2}, 95 \% \mathrm{Cl} 0.16-6.2 \mathrm{ml} / \mathrm{min} / 1.73 \mathrm{~m}^{2}, \mathrm{p}=0.039$ and this was consistent with results for serum creatinine. Statistically significant reductions in serum uric acid, systolic and diastolic blood pressure were found, favouring allopurinol. There were insufficient data on adverse events, incidence of ESRD and cardiovascular disease for analysis.

Conclusions: Adequately powered RCTs are needed to establish whether treatments that lower urate have beneficial renal and cardiovascular effects.

Keywords: Hyperuricemia, Chronic kidney disease, Urate lowering therapy, Allopurinol

\section{Background}

The prevalence of recognized chronic kidney disease (CKD) is increasing globally [1]. Patients with CKD have higher mortality rates and reduced quality of life relative to the general population [2]. They are also at a disproportionally higher cardiovascular risk, and most patients with CKD die of cardiovascular disease (CVD) rather than progress to end-stage renal disease (ESRD) [3]. The importance of finding modifiable risk factors that slow

\footnotetext{
*Correspondence: tahir.kanji@medportal.ca

'Michael G. DeGroote School of Medicine, McMaster University, Hamilton,

Ontario, Canada

${ }^{3}$ London Health Sciences Centre, 339 Windermere Road, London, Ontario N6G 2V4, Canada

Full list of author information is available at the end of the article
}

CKD progression or reduce cardiovascular risk cannot be understated.

Because low glomerular filtration rate (GFR) leads to hyperuricemia, CKD is associated with hyperuricemia and gout [4]. Hyperuricemia has also consistently been associated with incident CKD, though its association with progression of CKD has been less clear [5-27].

Currently, urate-lowering therapy (ULT) is only used for patients with clinical evidence of crystal deposition such as gout or urolithiasis [28]: routine prophylaxis of asymptomatic hyperuricemia is not recommended in current guidelines. This systematic review summarizes evidence from randomized controlled trials that examined 
whether treating patients with stages 3-5 CKD improves renal and cardiovascular outcomes.

\section{Methods}

Study selection

We included studies if their selection criteria specified estimated glomerular filtration rate (eGFR) $<60 \mathrm{ml} / \mathrm{min} /$ $1.73 \mathrm{~m}^{2}$ or their baseline mean eGFR or serum creatinine were $<60 \mathrm{ml} / \mathrm{min} / 1.73 \mathrm{~m}^{2}$ or $>137 \mu \mathrm{mol} / \mathrm{L}$ for men, and $>104 \mu \mathrm{mol} / \mathrm{L}$ for women, respectively $(>1.55 \mathrm{mg} / \mathrm{dL}$ for men and $>1.18 \mathrm{mg} / \mathrm{dL}$ for women) [29]. Any pharmacologic therapy given to lower uric acid was considered a suitable intervention. These included allopurinol, febuxostat, probenecid, sulfinpyrazone, benzbromarone, pegloticase and rasburicase. We included studies in which the comparator was placebo, usual therapy or an alternative drug. Outcomes of greatest interest were: serum creatinine level, eGFR, proteinuria, incidence of ESRD, incidence of cardiovascular events and cardiovascular mortality. Other outcomes were: serum uric acid level, blood pressure (diastolic and systolic), markers of inflammation (C-reactive protein levels), all-cause mortality, adverse events and serious adverse events. We included only RCTs and quasi-RCTs. We accepted any estimate of GFR, whether derived from serum creatinine and demographic variables, or from directly-measured creatinine or isotope clearance. We followed a prespecified protocol but this was not registered.

\section{Finding relevant studies}

In the primary search, citations were compiled from the following electronic databases: Ovid MEDLINE (1966June 2013), Ovid EMBASE (1980-June 2013), CENTRAL (June 2013) and Web of Science (June 2013) using search strategies detailed in the Additional file 1. We reviewed the Cochrane Collaboration's protocol and adapted some of their search terms [30]. The first arm of our search strategy included terms such as: kidney disease, renal insufficiency and renal replacement therapy as well as further synonyms and key words. These were combined with the second arm of our strategy comprising of terms such as allopurinol, gout suppressants, urate oxidase and further descriptors related to ULT. The citations were downloaded into Endnote, version X7 (Thompson ISI Research-Soft, Philadelphia, PA) and duplicate citations removed.

To further identify relevant studies, a secondary search was performed, making use of reference lists of previous narrative reviews [31-33] and of studies identified in the primary search, PubMed 'Related Articles' feature, published abstracts from two recent American Society of Nephrology (2010-2012) and International Society of Nephrology meetings (2010-2012), internet searches using Google Scholar, and trial registers from National Institute of Health and Current Controlled Trials. We also identified seven studies [34-40] from two recently published systematic reviews on a similar question [41,42].

Two authors (TK, MG) completed the first phase of screening using titles and abstracts (kappa of 0.84). Agreement for the second phase of screening, using fulltext manuscripts, was lower at a kappa of 0.41. All disagreements for both phases were resolved by consensus.

\section{Data abstraction and quality assessment}

Two authors (TK and MG) independently extracted data for each included study using standardized forms. Subsequently, quality assessment was also completed in duplicate (TK, MG) using the Cochrane Collaboration's Higgins Risk of Bias Assessment Tool [43]. Disagreements from both data abstraction and quality assessment were resolved through consensus. All the non-English language studies were written in Chinese; data was extracted and quality assessed by one author (TK), with the assistance of a translator.

\section{Data synthesis and meta-analysis}

Given the heterogeneity in duration of follow up and study comparators, we decided to meta-analyze studies greater than 3 months in duration that compared allopurinol to inactive control [34,36-40,44-48].

We used a random-effects model within Comprehensive Meta-analysis (Englewood NJ). Two of the studies did not report GFR estimates [46,48]: we used serum creatinine and demographic information from the studies, to estimate mean eGFR. The equations utilized were Modification of Diet in Renal Disease (MDRD) with Chinese coefficients where appropriate [49].

\section{Results}

Primary electronic database searches identified 5994 citations, which was reduced to 5497 citations by deduplication. We retrieved 32 full-text manuscripts from the electronic search and a further eight from secondary sources, of which 19 studies were relevant (Figure 1).

\section{Description of studies}

The 19 studies, published between 1998 and 2012, randomized 992 participants with duration of follow-up ranging from 2 days to 24 months; 16 were parallel group and 3 were crossover design (Table 1). The studies originated from 10 different countries, including the United States, United Kingdom, Iran, France, Italy, Greece, Spain and China. Most were single-centre and had relatively small sample sizes with short duration of follow up. Populations were variable and half the studies did not report usage of baseline renin-angiotensinaldosterone system (RAAS) blockade (Table 2). 


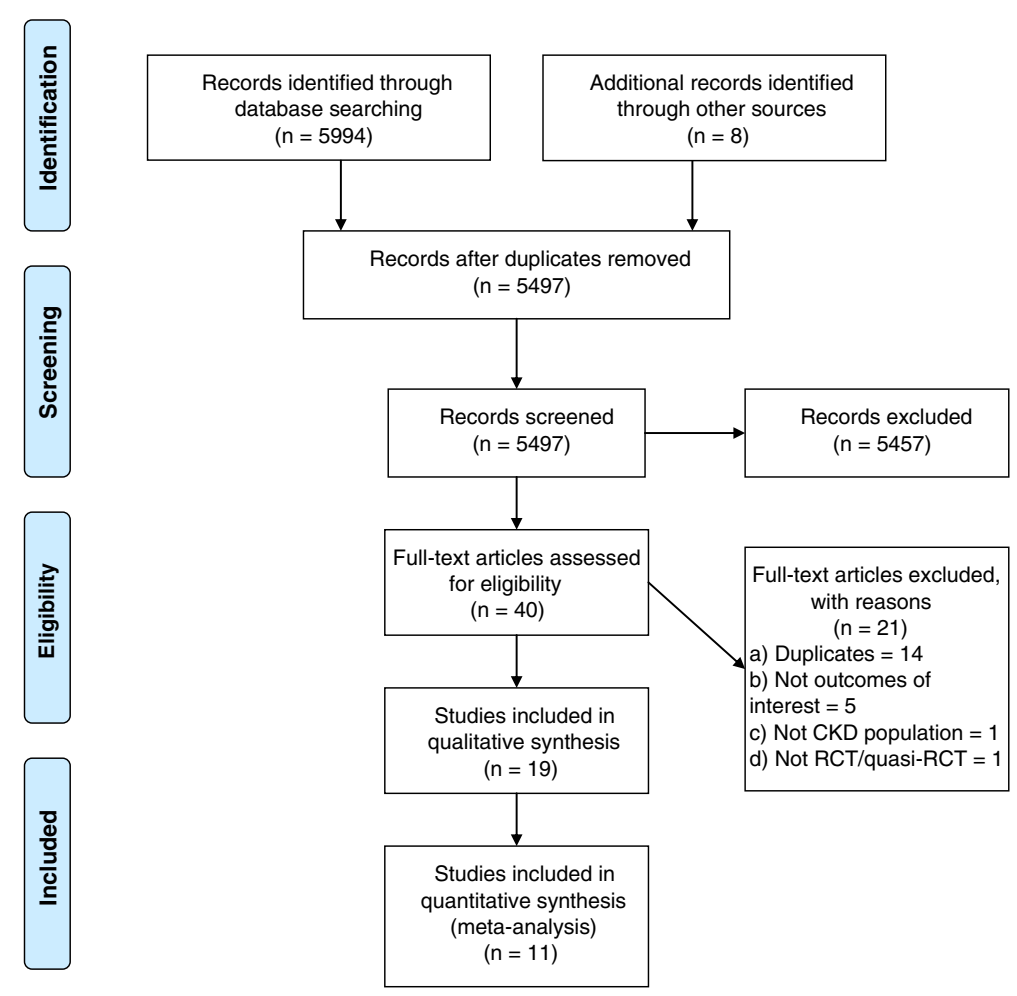

Figure 1 Flow diagram.

\section{Study results}

Pooled estimate of eGFR was in favour of allopurinol with a mean difference (MD) of $3.2 \mathrm{ml} / \mathrm{min} / 1.73 \mathrm{~m}^{2}$, $95 \%$ confidence interval $(\mathrm{CI}) \quad 0.16-6.2 \mathrm{ml} / \mathrm{min} / 1.73 \mathrm{~m}^{2}$, $\mathrm{p}=0.039$. Heterogeneity was measured with a $\mathrm{Q}$-value of 6.95 and $\mathrm{I}^{2}$ of $42.5, \mathrm{p}=0.138$. We performed a sensitivity analysis excluding studies in which we had calculated eGFR from serum creatinine: in this analysis, the tendency was in the same direction but the results did not meet formal statistical significance. Pooling of serum creatinine also favoured allopurinol with a mean difference of $0.63 \mathrm{mg} / \mathrm{dL}, 95 \%$ CI $0.43-0.83 \mathrm{mg} / \mathrm{dL}$. As expected, a statistically significant reduction in serum uric acid was found with a MD of $2.8 \mathrm{mg} / \mathrm{dL}, 95 \% \mathrm{CI}$ 2.3-3.4 $\mathrm{mg} / \mathrm{dL}, \mathrm{p}<0.001$. Notably reductions were found for both pooled estimates of systolic (MD $6.6 \mathrm{mmHg}, 95 \%$ CI 2.0-11.1 $\mathrm{mmHg}$ ) and diastolic blood pressure (MD $2.1 \mathrm{mmHg}$, 95\% CI 0.50-3.7 mmHg). Proteinuria showed a tendency towards benefit, again favouring allopurinol (Figure 2). A funnel plot was completed for serum creatinine, which showed mild asymmetry consistent with publication bias (Figure 3).

We did not meta-analyze trials of less than three months' duration, because we thought it biologically implausible that effects would be observable so rapidly. Three trials with less than one month of follow up did not show statistically significant differences in renal function [50-53]. There were three studies of between one and three months' duration: uricosuric amlodipine compared to tertatolol showed higher eGFR in the group treated with amlodipine [54]; creatinine clearance improved following a single dose infusion of rasburicase compared to placebo [55]; and there was a tendency towards higher eGFR in a comparison of benzbromarone to allopurinol [56].

There were insufficient data on adverse events, incidence of ESRD and cardiovascular events for metaanalysis. One study reported cardiovascular event rates finding a statistically significant reduction in cardiovascular risk comparing allopurinol to usual therapy after 24 months of follow-up (HR 0.29, 95\% CI 0.09-0.86, p = 0.026) [44]. No serious adverse events were noted in any of the included studies, specifically allopurinol hypersensitivity syndrome, toxic epidermal necrolysis or StevenJohnson syndrome.

\section{Risk of bias of included studies}

Overall, study quality was variable (Figure 4). The internal validity of the included RCTs was difficult to assess as most studies omitted important methodological details. Notably, some studies did not use an intentionto-treat analysis. We were not able to report quality features in one study as it was available in abstract form only [34]. Although a few of the studies were not 
Table 1 Study characteristics

\begin{tabular}{|c|c|c|c|c|c|c|c|c|}
\hline First author (Ref No.) & $\begin{array}{l}\text { Year of } \\
\text { publication }\end{array}$ & Journal & Location of trial & Study design & $\begin{array}{l}\text { Duration of } \\
\text { follow-up }\end{array}$ & $\begin{array}{l}\text { Sample } \\
\text { size }\end{array}$ & Treatment & Control \\
\hline Katholi [51] & 1998 & American Journal of Kidney Diseases & Springfield, Illinois & $\begin{array}{l}\text { Parallel Group RCT with } \\
2 \times 2 \text { factorial design }\end{array}$ & 2 days & 39 & Allopurinol & Placebo \\
\hline Perez-Ruiz [56] & 1999 & Journal of Clinical Rheumatology & Pais Vasco, Spain & Parallel Group RCT & 9-12 months & 36 & Benzbromarone & Allopurinol \\
\hline Kamper [50] & 2001 & Clinical Transplantation & Herlev, Denmark & Cross-over RCT & 2 weeks & 26 & Losartan & No treatment \\
\hline Schmidt [53] & 2001 & Nephrology Dialysis Transplantation & Vienna, Austria & Cross-over RCT & 3 weeks & 13 & Losartan & Enalapril \\
\hline Doehner [35] & 2002 & Circulation & London, UK & Cross-over RCT & 2 weeks & 14 & Allopurinol & Placebo \\
\hline Chanard [54] & 2003 & Nephrology Dialysis Transplantation & Three centres in France & Parallel Group RCT & 2 months & 48 & Amlodipine & Tertatolol \\
\hline Siu [48] & 2006 & American Journal of Kidney Diseases & Hong Kong, China & Parallel Group RCT & 12 months & 54 & Allopurinol & No treatment \\
\hline Liu [36] & 2007 & China Pharmacy & Guangzhou and Luzhou, China & Parallel Group RCT & 12 months & 47 & Allopurinol & No treatment \\
\hline Sarris [34] & 2007 & Nephrology Dialysis Transplantation & Athens, Greece & Parallel Group RCT & 12 months & 36 & Allopurinol & No treatment \\
\hline Lei [40] & 2009 & Shaanxi Medical Journal & Xi'an, China & Parallel Group RCT & 12 months & 57 & Allopurinol & No treatment \\
\hline Malaguarnera [55] & 2009 & Expert Opinion Pharmacotherapy & Catania, Italy & Parallel Group RCT & 2 months & 38 & Rasburicase & Placebo \\
\hline Nouri-Majalan [52] & 2009 & $\begin{array}{l}\text { Vascular Health and Risk } \\
\text { Management }\end{array}$ & Yazd, Iran & Parallel Group RCT & 5 days & 60 & Allopurinol and vitamin $\mathrm{E}$ & No treatment \\
\hline Deng [37] & 2010 & Journal of Practical Medicine & Beijing, China & Parallel Group RCT & 12 months & 68 & Allopurinol & No treatment \\
\hline Goicoechea [44] & 2010 & $\begin{array}{l}\text { Clinical Journal of American Soc of } \\
\text { Neph }\end{array}$ & Madrid, Spain & Parallel Group RCT & 24 months & 113 & Allopurinol & No treatment \\
\hline Momeni [46] & 2010 & Iranian Journal of Kidney Diseases & Isfahan, Iran & Parallel Group RCT & 4 months & 44 & Allopurinol & Placebo \\
\hline Shen [38] & 2010 & China Foreign Medical Treatment & Chengdu, China & Parallel Group RCT & 12 months & 52 & Allopurinol & No treatment \\
\hline Kao [45] & 2011 & Journal of American Soc of Neph & Dundee, UK & Parallel Group RCT & 9 months & 67 & Allopurinol & Placebo \\
\hline Tan [39] & 2011 & Modern Hospital & Guangzhou, China & Parallel Group RCT & 24 months & 140 & Allopurinol & No treatment \\
\hline Shi [47] & 2012 & Kidney and Blood Pressure Research & Guangzhou, China & Parallel Group RCT & 6 months & 40 & Allopurinol & No treatment \\
\hline
\end{tabular}


Table 2 Study population characteristics

\begin{tabular}{|c|c|c|c|c|c|c|c|c|}
\hline $\begin{array}{l}\text { First author } \\
\text { (Ref. No.) }\end{array}$ & Population & $\begin{array}{l}\text { BL RAAS } \\
\text { blockade }\end{array}$ & Tx age & Ct age & $\begin{array}{l}\text { Tx gender } \\
\text { (F:M or \% male) }\end{array}$ & $\begin{array}{l}\text { Ct gender } \\
\text { (F:M or \% male) }\end{array}$ & $\begin{array}{l}\text { Tx SUA baseline } \\
(\mathrm{mg} / \mathrm{dL})\end{array}$ & $\begin{array}{l}\text { Ct SUA baseline } \\
(\mathrm{mg} / \mathrm{dL})\end{array}$ \\
\hline Katholi [51] & $\mathrm{s} C \mathrm{r} 1.4-2.0 \mathrm{mg} / \mathrm{dl}$ and rec contrast & Excluded & $\begin{array}{l}60 \pm 4 \text { (NMg), } \\
61 \pm 3(\mathrm{LoMg})\end{array}$ & $\begin{array}{l}59 \pm 5 \text { (NMg) } \\
63 \pm 4 \text { (LoMg) }\end{array}$ & Not reported & Not reported & Not reported & Not reported \\
\hline Perez-Ruiz [56] & Chronic Gout with $\mathrm{CrCl} 20-80$ & Not reported & $60.9 \pm 12.8$ & $67.3 \pm 9.59$ & Not reported & Not reported & $9.35 \pm 1.96$ & $8.96 \pm 1.84$ \\
\hline Kamper [50] & HTN CsA Renal Tr & Minority & $\begin{array}{l}\text { M median age } 47, \\
\text { W median age } 47\end{array}$ & N/A & 10:16 & N/A & $\begin{array}{l}7.90 \text { (median), } \\
4.87-11.60 \text { (range) }\end{array}$ & N/A \\
\hline Schmidt [53] & HTN CsA Renal Tr & Not reported & $58 \pm 12$ & N/A & 1:12 & N/A & $7.8 \pm 2.2$ & $7.8 \pm 1.8$ \\
\hline Doehner [35] & LV dysfxn (EF < 40\%), hyperUA >400 umol/L & Not reported & $68 \pm 2$ & $69 \pm 3$ & $100 \%$ male & $100 \%$ male & $8.99 \pm 0.37$ & $9.88 \pm 0.62$ \\
\hline Chanard [54] & HTN CsA Renal Tr & Not reported & $45.2 \pm 9.9$ & $48.2 \pm 11.5$ & 7:17 & $8: 16$ & $8.11 \pm 1.66$ & $7.56 \pm 1.65$ \\
\hline Siu [48] & $\mathrm{sCr} 120-400 \mathrm{umol} / \mathrm{L}$ & Majority & $47.7 \pm 12.9$ & $48.8 \pm 16.8$ & $9: 4$ & 13:15 & $9.75 \pm 1.18$ & $9.92 \pm 1.68$ \\
\hline Liu [36] & CKD (120-400 umol/L) and hyperUA & Not reported & $45.6 \pm 12.5$ & $46.5 \pm 13.8$ & $8: 16$ & 10:13 & $9.73 \pm 0.20$ & $9.92 \pm 0.26$ \\
\hline Sarris [34] & $\begin{array}{l}\text { hyperUA }>7 \mathrm{mg} / \mathrm{dL} \text {, mild-mod CKD, } \\
\mathrm{s} C r>1.5,<3.0 \mathrm{mg} / \mathrm{dL}\end{array}$ & Not reported & $49.2 \pm 17.3$ & $50.4 \pm 15.8$ & $8: 10$ & $11: 7$ & $8.88 \pm 1.26$ & $9.16 \pm 1.46$ \\
\hline Lei [40] & CKD with hyperUA & Not reported & $48.6 \pm 10.2$ & $49.5 \pm 9.8$ & 9:20 & 9:19 & $8.84 \pm 1.45$ & $8.70 \pm 1.41$ \\
\hline Malaguarnera [55] & hyperUA, 65-85 yrs, sCr 2.5 mg/dl & Approximately half & $75.6 \pm 8.4$ & $76.4 \pm 8.1$ & 15:5 & $12: 6$ & $10.9 \pm 2.9$ & $10.3 \pm 3.1$ \\
\hline Nouri-Majalan [52] & Pts undergoing $C A B G$ and eGFR $<60$ & Not reported & $65 \pm 9.5$ & $61 \pm 7.90$ & 13:17 & 16:14 & Not reported & Not reported \\
\hline Deng [37] & CKD & Not reported & $60.0 \pm 11.1$ & $58.8 \pm 9.4$ & 15:14 & 14:18 & $8.59 \pm 1.01$ & $8.93 \pm 0.96$ \\
\hline Goicoechea [44] & CKD Stage 3-5 & Majority & $72.1 \pm 7.9$ & $71.4 \pm 9.5$ & Not reported & Not reported & $7.8 \pm 2.1$ & $7.3 \pm 1.6$ \\
\hline Momeni [46] & T2DM Nephropathy & Majority & $56.3 \pm 10.6$ & $59.1 \pm 10.6$ & 11:9 & 11:9 & $5.96 \pm 1.21$ & $6.5 \pm 2.2$ \\
\hline Shen [38] & CKD with hyperUA & Not reported & $47.1 \pm 11.8$ & $47.6 \pm 12.4$ & 8:18 & 9:17 & $9.01 \pm 1.38$ & $8.89 \pm 1.50$ \\
\hline Kao [45] & LVH and CKD Stage 3 & Majority & $70.6 \pm 6.9$ & $73.7 \pm 5.3$ & $59 \%$ male & $46 \%$ male & $7.39 \pm 1.5$ & $7.06 \pm 1.3$ \\
\hline $\operatorname{Tan}[39]$ & T2DM nephropathy eGFR, 30-60 ml/min/1.73 m² & Majority & $59.3 \pm 9.2$ & $58.6 \pm 8.3$ & $35: 37$ & 33:35 & $8.93 \pm 0.96$ & $8.60 \pm 1.01$ \\
\hline Shi [47] & IgA nephropathy and hyperUA & Excluded & $39.7 \pm 10.0$ & $40.1 \pm 10.8$ & 8:13 & 10:9 & $7.9 \pm 1.1$ & $7.8 \pm 1.1$ \\
\hline
\end{tabular}




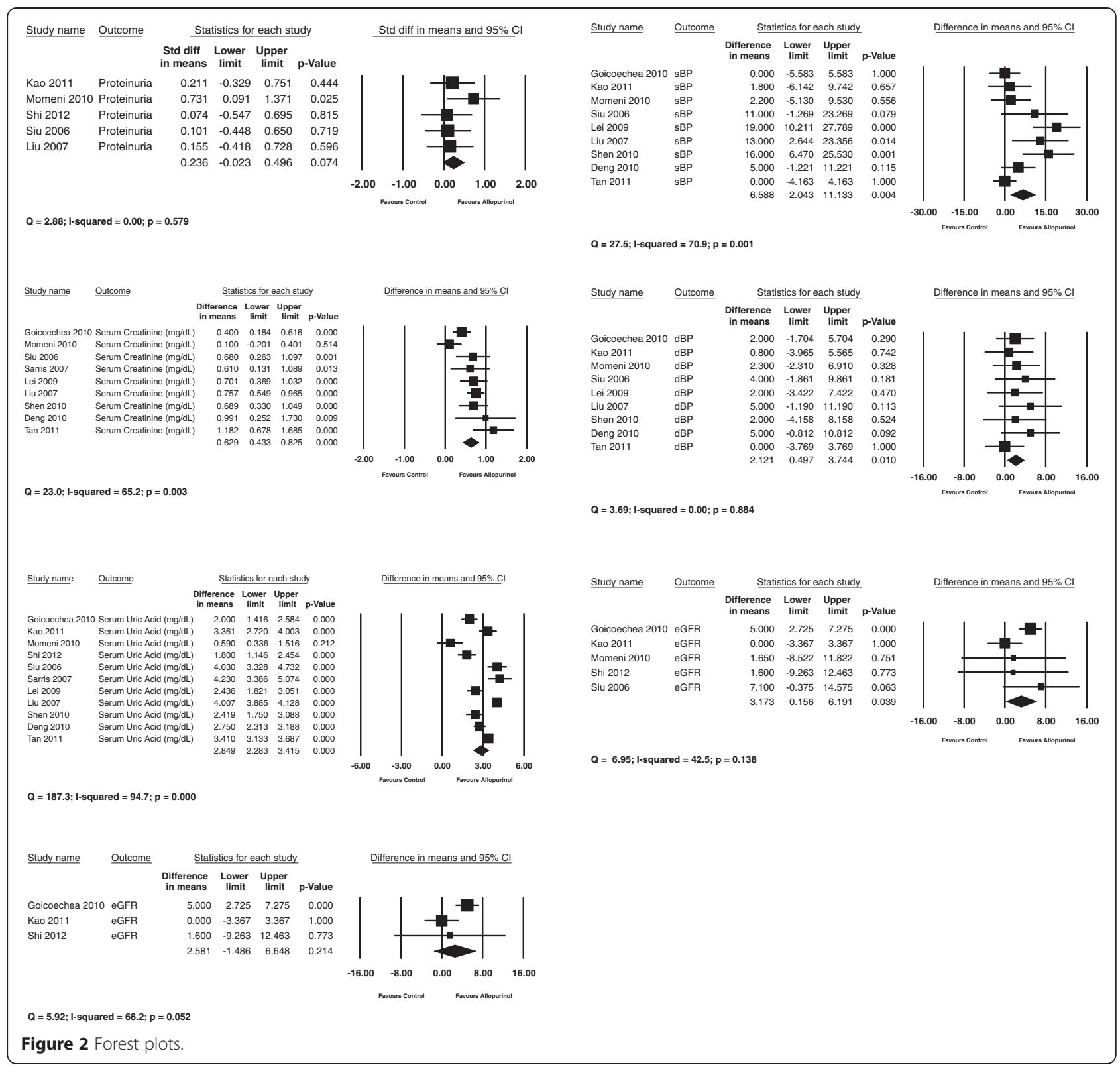

placebo-controlled, we did not assess this as a high risk of bias per se since our outcomes of interest were objective.

\section{Discussion}

In our meta-analysis of RCTs of treatments to lower serum urate, we observed a small but potentially clinically important and statistically significant improvement in eGFR and serum creatinine, favouring allopurinol. There were also statistically significant reductions in systolic and diastolic blood pressure, and serum uric acid, as expected. A tendency towards benefit for proteinuria was shown as well.
Strengths of our review include its comprehensiveness and robust methodology. Limitations include the quality of our individual studies. Many of our included trials are small, single-centre studies with relatively short duration of follow-up. Two of our longest studies both had no placebo arm and were open-label trials $[44,48]$. Also, two of our included trials did not report estimates of GFR; we converted serum creatinine into eGFR values using mean demographic variables, which is a reasonable assumption, but one which increases measurement area for these values. We conducted a sensitivity analysis on data that did not require these calculations, finding a similar result but one that lacked statistical significance. 


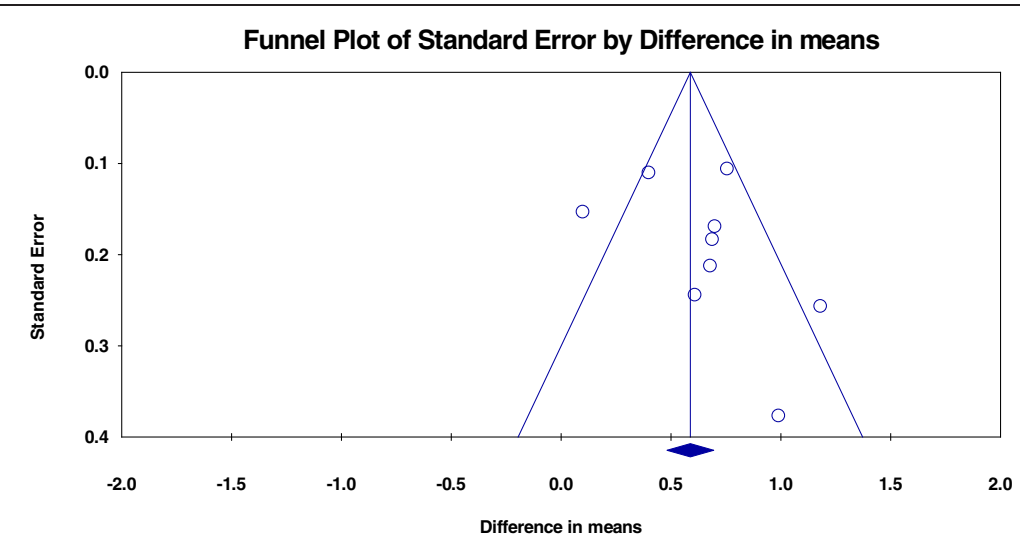

Figure 3 Risk of bias assessment.

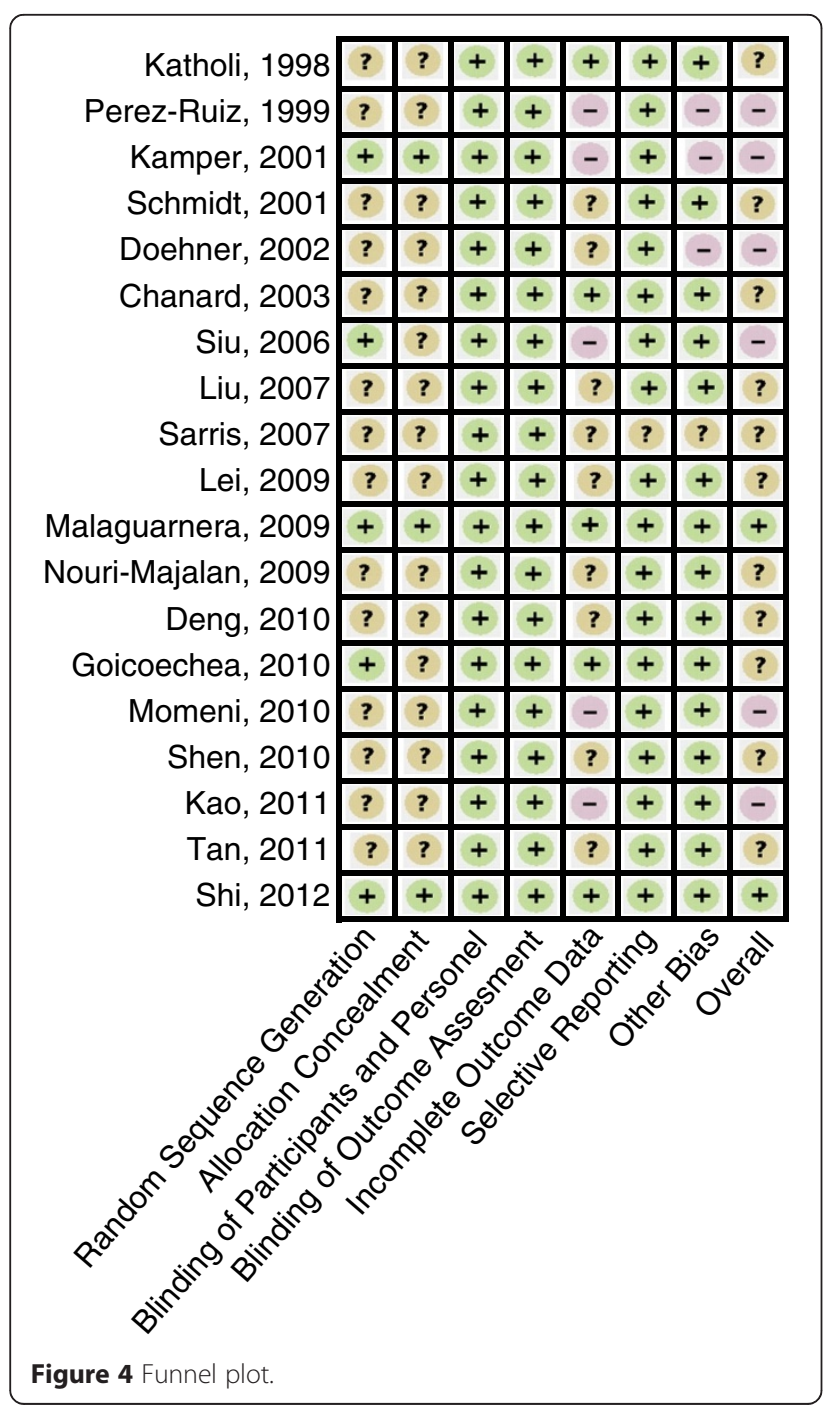

We are aware of two recently published systematic reviews of this question [42,41]. Bose and colleagues conducted a comprehensive search of the English literature and similarly identified the scarcity of robust data on which to draw conclusions. Wang and colleagues searched up to December 2011, however, they incorporated Chinese databases resulting in several non-English RCTs. Our meta-analysis adds to these by the more recent search date, including data on calculated eGFR from studies that reported only serum creatinine as well as reporting effects on blood pressure as an outcome. The Cochrane Renal Group also is in the process of conducting a review; their protocol is published [30].

We do not know the mechanism by which allopurinol, or other urate-lowering therapy, is nephroprotective. Xanthine oxidase produces reactive oxygen species (ROS) and its inhibition with allopurinol may reduce oxidative stress [33]. However, it is difficult to differentiate if such effects are secondary to the lowering of uric acid per se or inhibition of a ROS-producing enzyme.

In rats with remnant kidneys, oxonic-acid induced hyperuricemia accelerates glomerulosclerosis and tubulointerstitial fibrosis $[57,58]$. Micropuncture studies in these same models suggest preglomerular arteriolar disease alters renal autoregulation, resulting in systemic and glomerular hypertension [59]. In all of these studies, correction of the hyperuricemic state with a uricosuric agent can significantly improve blood pressure control, decrease proteinuria, and slow progression of kidney disease $[57,59,58]$. Further studies may consider concurrently measuring markers of oxidative stress, inflammation, and blood pressure parameters to better understand mechanisms of a potential benefit.

We also take note of the recently published long-term follow up study of Goicoechea et al., lending further support to treating urate in CKD. Their adjusted hazard ratios for reduction of renal and cardiovascular events were 0.32 , with a $95 \%$ CI of $0.15-0.69, \mathrm{p}=0.004$, and 
0.43 with a $95 \%$ CI of $0.21-0.88, \mathrm{p}=0.02$, respectively. Notably, the definition of their renal endpoints entailed initiation of dialysis therapy and doubling of serum creatinine. However, again their data is limited by small sample size and single-centre design. Also, as the study was a post-hoc analysis, it did not require patients to adhere to previous randomly allocated treatment arms [60].

\section{Conclusions}

Though the data we summarize here are suggestive and encouraging, using allopurinol in clinical practice to delay progression of CKD would be premature. Given these limitations, studies powered to measure reduction in patient-important renal composites are necessary, and are in progress [61-63].

\section{Additional file}

Additional file 1: Database search strategies.

\section{Abbreviations}

ACE: Angiotensin-converting enzyme; BL: Baseline; CABG: Coronary artery bypass grafting; Cl: Confidence interval; CKD: Chronic kidney disease; $\mathrm{CrCl}$ : Creatinine clearance; CsA: Cyclosporine-treated; Ct: Control group; CVD: Cardiovascular disease; EF: Ejection fraction; eGFR: Estimated glomerular filtration rate; ESRD: End-stage renal disease; HR: Hazard ratio; HTN: Hypertensive; hyperUA: Hyperuricemic; MD: Mean difference; LMg: Low magnesium group; LV dysfxn: Left ventricular dysfunction; LVH: Left ventricular hypertrophy; NMg: Normal magnesium group; RAAS: Renin-angiotensin-aldosterone system; RCT: Randomized controlled trial; ROS: Reactive oxygen species; sCr: Serum creatinine; SUA: Serum uric acid; T2DM: Type 2 diabetes mellitus; TGF $\beta$ : Transforming growth factor beta; Tr: Transplant patients; Tx: Treatment group.

\section{Competing interests}

The authors declare that they have no competing interests.

\section{Authors' contributions}

TK screened, data abstracted, quality appraised and drafted the manuscript. MG secondarily screened, data abstracted and quality appraised. CC assisted with the statistical analysis and editing of the manuscript. RY conceived of the study, participated in its design and coordination as well as editing of the manuscript. All authors read and approved the final manuscript.

\section{Acknowledgements}

Tahir Kanji was supported by a Canadian Institute of Health Research Health Professional Student Research Award. We thank Emma Irvin-Sinkins for her assistance with methodological aspects of the review. We also thank Edison Wang for his assistance with the translation of non-English studies.

\section{Author details}

${ }^{1}$ Michael G. DeGroote School of Medicine, McMaster University, Hamilton, Ontario, Canada. ${ }^{2}$ Department of Medicine, Division of Nephrology, McMaster University, Hamilton, Ontario, Canada. ${ }^{3}$ London Health Sciences Centre, 339 Windermere Road, London, Ontario N6G 2V4, Canada.

Received: 24 November 2014 Accepted: 1 April 2015

Published online: 19 April 2015

\section{References}

1. Levey AS, Atkins R, Coresh J, Cohen EP, Collins AJ, Eckardt KU, et al. Chronic kidney disease as a global public health problem: approaches and initiatives - a position statement from kidney disease improving global outcomes. Kidney Int. 2007;72(3):247-59.
2. Gorodetskaya I, Zenios S, McCulloch CE, Bostrom A, Hsu CY, Bindman AB, et al. Health-related quality of life and estimates of utility in chronic kidney disease. Kidney Int. 2005;68(6):2801-8.

3. Hajhosseiny R, Khavandi K, Goldsmith DJ. Cardiovascular disease in chronic kidney disease: untying the Gordian knot. Int J Clin Pract. 2013;67(1):14-31. doi:10.1111/j.1742-1241.2012.02954.x.

4. Talbott JH, Terplan KL. The kidney in gout. Medicine (Baltimore). 1960;39:405-67.

5. Altemtam N, Russell J, El Nahas M. A study of the natural history of diabetic kidney disease (DKD). Nephrol Dial Transplant. 2012;27(5):1847-54.

6. Bellomo G, Venanzi S, Verdura C, Saronio P, Esposito A, Timio M. Association of uric acid with change in kidney function in healthy normotensive individuals. Am J Kidney Dis. 2010;56(2):264-72.

7. Ben-Dov IZ, Kark JD. Serum uric acid is a GFR-independent long-term predictor of acute and chronic renal insufficiency: the Jerusalem Lipid Research Clinic cohort study. Nephrol Dial Transplant. 2011;26(8):2558-66.

8. Chonchol M, Shlipak MG, Katz R, Sarnak MJ, Newman AB, Siscovick DS, et al. Relationship of uric acid with progression of kidney disease. Am J Kidney Dis. 2007:50(2):239-47.

9. Domrongkitchaiporn S, Sritara P, Kitiyakara C, Stitchantrakul W, Krittaphol V, Lolekha P, et al. Risk factors for development of decreased kidney function in a southeast Asian population: a 12-year cohort study. J Am Soc Nephrol. 2005;16(3):791-9.

10. Ficociello LH, Rosolowsky ET, Niewczas MA, Maselli NJ, Weinberg JM, Aschengrau $A$, et al. High-normal serum uric acid increases risk of early progressive renal function loss in type 1 diabetes: results of a 6-year follow-up. Diabetes Care. 2010;33(6):1337-43.

11. Hsu CY, Iribarren C, McCulloch CE, Darbinian J, Go AS. Risk factors for endstage renal disease: 25-year follow-up. Arch Intern Med. 2009;169(4):342-50.

12. Iseki K, Ikemiya Y, Inoue T, Iseki C, Kinjo K, Takishita S. Significance of hyperuricemia as a risk factor for developing ESRD in a screened cohort. Am J Kidney Dis. 2004:44(4):642-50.

13. Iseki K, Oshiro S, Tozawa M, Iseki C, Ikemiya Y, Takishita S. Significance of hyperuricemia on the early detection of renal failure in a cohort of screened subjects. Hypertens Res. 2001;24(6):691-7.

14. Ishani A, Grandits GA, Grimm RH, Svendsen KH, Collins AJ, Prineas RJ, et al. Association of single measurements of dipstick proteinuria, estimated glomerular filtration rate, and hematocrit with 25-year incidence of endstage renal disease in the multiple risk factor intervention trial. J Am Soc Nephrol. 2006:17(5):1444-52.

15. Jalal DI, Rivard CJ, Johnson RJ, Maahs DM, McFann K, Rewers M, et al. Serum uric acid levels predict the development of albuminuria over 6 years in patients with type 1 diabetes: findings from the Coronary Artery Calcification in Type 1 Diabetes study. Nephrol Dial Transplant. 2010;25(6):1865-9.

16. Kuo CF, Luo SF, See LC, Ko YS, Chen YM, Hwang JS, et al. Hyperuricaemia and accelerated reduction in renal function. Scand J Rheumatol. 2011;40(2):116-21.

17. Madero M, Sarnak MJ, Wang X, Greene T, Beck GJ, Kusek JW, et al. Uric acid and long-term outcomes in CKD. Am J Kidney Dis. 2009;53(5):796-803.

18. Mok Y, Lee SJ, Kim MS, Cui W, Moon YM, Jee SH. Serum uric acid and chronic kidney disease: the Severance cohort study. Nephrol Dial Transplant. 2012;27(5):1831-5.

19. Obermayr RP, Temml C, Gutjahr G, Knechtelsdorfer M, Oberbauer R, KlauserBraun R. Elevated uric acid increases the risk for kidney disease. J Am Soc Nephrol. 2008;19(12):2407-13.

20. Ohno I, Hosoya T, Gomi H, Ichida K, Okabe H, Hikita M. Serum uric acid and renal prognosis in patients with IgA nephropathy. Nephron. 2001;87(4):333-9.

21. Sonoda H, Takase H, Dohi Y, Kimura G. Uric acid levels predict future development of chronic kidney disease. Am J Nephrol. 2011;33(4):352-7.

22. Sturm G, Kollerits B, Neyer U, Ritz E, Kronenberg F, Group MS. Uric acid as a risk factor for progression of non-diabetic chronic kidney disease? The Mild to Moderate Kidney Disease (MMKD) Study. Exp Gerontol. 2008;43(4):347-52.

23. Syrjanen J, Mustonen J, Pasternack A. Hypertriglyceridaemia and hyperuricaemia are risk factors for progression of IgA nephropathy. Nephrol Dial Transplant. 2000;15(1):34-42.

24. Wang S, Shu Z, Tao Q, Yu C, Zhan S, Li L. Uric acid and incident chronic kidney disease in a large health check-up population in Taiwan. Nephrology (Carlton). 2011;16(8):767-76.

25. Weiner DE, Tighiouart H, Elsayed EF, Griffith $J$, Salem DN, Levey AS. Uric acid and incident kidney disease in the community. J Am Soc Nephrol. 2008;19(6):1204-11. 
26. Yen CJ, Chiang CK, Ho LC, Hsu SH, Hung KY, Wu KD, et al. Hyperuricemia associated with rapid renal function decline in elderly Taiwanese subjects. J Formos Med Assoc. 2009;108(12):921-8.

27. Zoppini G, Targher G, Chonchol M, Ortalda V, Abaterusso C, Pichiri l, et al. Serum uric acid levels and incident chronic kidney disease in patients with type 2 diabetes and preserved kidney function. Diabetes Care. 2012;35(1):99-104.

28. Khanna D, Fitzgerald JD, Khanna PP, Bae S, Singh MK, Neogi T, et al. 2012 American College of Rheumatology guidelines for management of gout. Part 1: systematic nonpharmacologic and pharmacologic therapeutic approaches to hyperuricemia. Arthritis Care Res. 2012;64(10)):1431-46. doi:10.1002/acr.21772.

29. Couchoud C, Pozet N, Labeeuw M, Pouteil-Noble C. Screening early renal failure: cut-off values for serum creatinine as an indicator of renal impairment. Kidney Int. 1999;55(5):1878-84.

30. Sampson AL, Singer RF, Walters G. Uric acid lowering therapies for preventing or delaying the progression of chronic kidney disease. Cochrane Database Syst Rev. 2011(11). doi:10.1002/14651858.CD009460

31. Badve SV, Brown F, Hawley CM, Johnson DW, Kanellis J, Rangan GK, et al. Challenges of conducting a trial of uric-acid-lowering therapy in CKD. Nat Rev Nephrol. 2011;7(5):295-300.

32. Filiopoulos V, Hadjiyannakos D, Vlassopoulos D. New insights into uric acid effects on the progression and prognosis of chronic kidney disease. Ren Fail. 2012;34(4):510-20.

33. Jalal DI, Chonchol M, Chen W, Targher G. Uric acid as a target of therapy in CKD. Am J Kidney Dis. 2013;61(1):134-46.

34. Sarris E, Bagiatudi G, Stavrianaki D, Salpigidis K, Siakotos M. Use of allopurinol in slowing the progression of chronic renal disease (abstract). Nephrol Dial Transplant. 2007;22:vi61.

35. Doehner W, Schoene N, Rauchhaus M, Leyva-Leon F, Pavitt DV, Reaveley DA, et al. Effects of xanthine oxidase inhibition with allopurinol on endothelial function and peripheral blood flow in hyperuricemic patients with chronic heart failure: results from 2 placebo-controlled studies. Circulation. 2002;105:2619-24.

36. Liu J, Sheng D. Allopurinol in lowering serum uric acid level for the delay of the progression of chronic renal disease. China Pharmacy. 2007;18(32):2524-5.

37. Deng $\mathrm{YH}$, Zhang $\mathrm{P}$, Liu H, Jia Q. Observation on allopurinol in lowering blood uric acid for slowing the progression of chronic renal failure. J Pract Med. 2010;26(6):982-4.

38. Shen H, Liu D. Clinical research on allopurinol in lowering serum uric acid level for the delay of the progression of chronic renal disease. China Foreign Medical Treatment. 2010;12:88-9.

39. Tan Y, Fu JZ, Liang M, Lin ZX, Huang J. Clinical observation of the effect of allopurinol to protect renal function in patients with diabetic nephropathy. Mod Hosp. 2011:11(6):36-8.

40. Lei J, Li ST. Clinical research on allopurinol lowering of uric acid level of chronic renal disease for the delay of the progression of renal disease. Shaanxi Med J. 2009;38:1191-212.

41. Wang $H$, Wei $Y$, Xianglei $K, X u$ D. Effects of urate-lowering therapy in hyperuricemia on slowing the progression of renal function: a metaanalysis. J Ren Nutr. 2013;23(5):389-96.

42. Bose B, Badve SV, Hiremath SS, Boudville N, Brown FG, Cass A, et al. Effects of uric acid-lowering therapy on renal outcomes: a systematic review and meta-analysis. Nephrol Dial Transplant. 2014;29(2):406-13. doi:10.1093/ndt/ gft378.

43. Higgins JP, Altman DG, Gotzsche $P C$, Juni $P$, Moher D, Oxman AD, et al. The Cochrane Collaboration's tool for assessing risk of bias in randomised trials. BMJ. 2011;343:d5928.

44. Goicoechea M, de Vinuesa SG, Verdalles U, Ruiz-Caro C, Ampuero J, Rincon $A$, et al. Effect of allopurinol in chronic kidney disease progression and cardiovascular risk. Clin J Am Soc Nephrol. 2010;5(8):1388-93.

45. Kao MP, Ang DS, Gandy SJ, Nadir MA, Houston JG, Lang CC, et al. Allopurinol benefits left ventricular mass and endothelial dysfunction in chronic kidney disease. J Am Soc Nephrol. 2011;22(7):1382-9.

46. Momeni A, Shahidi S, Seirafian S, Taheri S, Kheiri S. Effect of allopurinol in decreasing proteinuria in type 2 diabetic patients. Iran J Kidney Dis. 2010:4(2):128-32.

47. Shi Y, Chen W, Jalal D, Li Z, Chen W, Mao H, et al. Clinical outcome of hyperuricemia in IgA nephropathy: a retrospective cohort study and randomized controlled trial. Kidney Blood Press Res. 2012;35(3):153-60.
48. Siu YP, Leung KT, Tong MK, Kwan TH. Use of allopurinol in slowing the progression of renal disease through its ability to lower serum uric acid level. Am J Kidney Dis. 2006;47(1):51-9.

49. Ho E, Teo BW. Assessing kidney function in Asia. Singapore Med J. 2010;51(11):888-93.

50. Kamper AL, Nielsen AH. Uricosuric effect of losartan in patients with renal transplants. Transplantation. 2001;72(4):671-4.

51. Katholi RE, Woods Jr WT, Taylor GJ, Deitrick CL, Womack KA, Katholi CR, et al. Oxygen free radicals and contrast nephropathy. Am J Kidney Dis. 1998;32(1):64-71.

52. Nouri-Majalan N, Ardakani EF, Forouzannia K, Moshtaghian H. Effects of allopurinol and vitamin $\mathrm{E}$ on renal function in patients with cardiac coronary artery bypass grafts. Vasc Health Risk Manag. 2009;5(2):489-94.

53. Schmidt A, Gruber U, Bohmig G, Koller E, Mayer G. The effect of ACE inhibitor and angiotensin II receptor antagonist therapy on serum uric acid levels and potassium homeostasis in hypertensive renal transplant recipients treated with CSA. Nephrol Dial Transplant. 2001;16(5):1034-7.

54. Chanard J, Toupance O, Lavaud S, Hurault de Ligny B, Bernaud C, Moulin B. Amlodipine reduces cyclosporin-induced hyperuricaemia in hypertensive renal transplant recipients. Nephrol Dial Transplant. 2003;18(10):2147-53.

55. Malaguarnera M, Vacante M, Russo C, Dipasquale G, Gargante MP, Motta M. A single dose of rasburicase in elderly patients with hyperuricaemia reduces serum uric acid levels and improves renal function. Expert Opin Pharmacother. 2009;10(5):737-42.

56. Perez-Ruiz F, Calabozo M, Fernandez-Lopez MJ, Herrero-Beites A, Ruiz-Lucea E, Garcia-Erauskin G, et al. Treatment of chronic gout in patients with renal function impairment: an open, randomized, actively controlled study. J Clin Rheumatol. 1999:5(2):49-55.

57. Kang DH, Nakagawa T, Feng L, Watanabe S, Han L, Mazzali M, et al. A role for uric acid in the progression of renal disease. J Am Soc Nephrol. 2002;13(12):2888-97.

58. Sanchez-Lozada LG, Tapia E, Soto V, Avila-Casado C, Franco M, Wessale JL, et al. Effect of febuxostat on the progression of renal disease in 5/6 nephrectomy rats with and without hyperuricemia. Nephron Physiol. 2008;108(4):69-78.

59. Sanchez-Lozada LG, Tapia E, Santamaria J, Avila-Casado C, Soto V, Nepomuceno $\mathrm{T}$, et al. Mild hyperuricemia induces vasoconstriction and maintains glomerular hypertension in normal and remnant kidney rats. Kidney Int. 2005;67(1):237-47.

60. Goicoechea M, Garcia de Vinuesa S, Verdalles U, Verde E, Macias N, Santos A, et al. Allopurinol and progression of CKD and cardiovascular events: long-term follow-up of a randomized clinical trial. Am J Kidney Dis. 2015. doi:10.1053/j.ajkd.2014.11.016.

61. Hosoya T, Kimura K, Itoh S, Inaba M, Uchida S, Tomino Y, et al. The effect of febuxostat to prevent a further reduction in renal function of patients with hyperuricemia who have never had gout and are complicated by chronic kidney disease stage 3: study protocol for a multicenter randomized controlled study. Trials. 2014;15:26. doi:10.1186/1745-6215-15-26.

62. Johnson D. The CKD-FIX trial: controlled trial of slowing of kidney disease progression from the inhibition of xanthine oxidase. Australian New Zealand Clinical Trials Registry. 2011.

63. Doria AaM, M. PERL: A Multicenter Clinical Trial of Allopurinol to Prevent GFR Loss in T1D. ClinicalTrialsgov. 2013.

\section{Submit your next manuscript to BioMed Central and take full advantage of:}

- Convenient online submission

- Thorough peer review

- No space constraints or color figure charges

- Immediate publication on acceptance

- Inclusion in PubMed, CAS, Scopus and Google Scholar

- Research which is freely available for redistribution 